\title{
Does HSP90 play an important role in psoriasis?
}

\author{
Rafał Czajkowski ${ }^{1}$, Sebastian Kaszewski², Tadeusz Tadrowski ${ }^{1}$, Dariusz Grzanka ${ }^{3}$, Justyna Ziandarska ${ }^{1}$, Gerard Drewa ${ }^{4}$, \\ Luiza Marek-Józefowicz ${ }^{1}$
}

\author{
'Department of Dermatology and Venerology, Faculty of Medicine, Ludwik Rydygier Medical College in Bydgoszcz, Nicolaus Copernicus \\ University in Torun, Poland \\ 2University Hospitals Coventry and Warwickshire NHS Trust, United Kingdom \\ ${ }^{3}$ Department of Clinical Pathomorphology, Faculty of Medicine, Ludwik Rydygier Medical College in Bydgoszcz, Nicolaus Copernicus \\ University in Torun, Poland \\ ${ }^{4}$ University of Bydgoszcz, Poland
}

Adv Dermatol Allergol 2021; XXXVIII (2): 319-326

DOI: https://doi.org/10.5114/ada.2021.106210

\begin{abstract}
Introduction: Psoriasis is a chronic, inflammatory skin disease. Environmental, genetic, autoinflammatory and autoimmune factors play a role in the pathogenesis of disease. It is believed that heat shock protein 90 (HSP90) is an interleukin-17 (IL-17) receptor, which plays an essential role in the psoriasis pathogenesis.

Aim: To evaluate the expression of the gene encoding HSP90 protein in keratinocytes of patients with psoriasis depending on its duration, recurrences, exacerbating factors, therapy form, and the coexistence of metabolic disorders and cardiovascular diseases.

Material and methods: Skin samples from 40 psoriatic patients were investigated in this study. Control skin biopsies were collected from 20 healthy volunteers. HSP90 expression level was measured by qRT-PCR reaction.

Results: This study has shown an increased mRNA expression of HSP90 in psoriatic patients as compared to healthy volunteers. A positive correlation of HSP90 expression and the frequency of exacerbations was found. A negative correlation between the HSP90 activity and the age of patients was demonstrated in the coexistence of psoriasis with hyperlipidaemia or diabetes. Among the factors exacerbating psoriasis, acute infections induced HSP90 expression most significantly.

Conclusions: HSP90 plays a role in the pathogenesis of psoriasis. The expression of HSP9O increases with the frequency of exacerbations of psoriasis throughout the year. Hyperlipidaemia or diabetes associated with psoriasis in young adults, and acute infections and emotional stress increase the expression of HSP90. The expression of HSP9O in psoriatic patients is not dependent on the type of psoriasis, comorbidity of cardiovascular diseases, smoking and alcohol addiction.
\end{abstract}

Key words: heat shock proteins, HSP90, psoriasis.

\section{Introduction}

Psoriasis is a chronic, inflammatory skin disease depending on the genetic predisposition as well as on autoinflammatory, autoimmune and environmental factors. Psoriasis is characterized by hyperproliferation of keratinocytes [1]. This disease is affecting approximately $2-3 \%$ of the population worldwide [2-6]. Prevalence of psoriasis depends, among others, on geographic location and racial origin. Psoriasis most often affects people who have white skin, less often Asians, and the least often is seen in the Black population. Psoriasis predisposes to the development of disorders of other systems and organs, including the cardiovascular system and joints. It is believed that psoriasis might be an independent risk factor for acute coronary syndromes and sudden cardiac death $[7,8]$. Men with severe psoriasis die on average 3.5 years earlier, whereas women on average 4.4 years earlier than individuals from the general population [9]. In genetically predisposed individuals, specified environmental factors can elicit the development of psoriasis. Although for many years scientific research has been intensively conducted to investigate the causes of the

Address for correspondence: Luiza Marek-Józefowicz, Department of Dermatology and Venerology, Faculty of Medicine, Ludwik Rydygier Medical College, Nicolaus Copernicus University, Bydgoszcz, Poland, e-mail: lui06@interia.pl Received: 30.01.2021, accepted: 21.02.2021. 
psoriasis development, the process is still not fully understood. To date, results of conducted studies have indicated that disturbances of cytokines play a predominant role [4]. Initially, clinicians and researchers who were trying to understand the mechanism of psoriatic plaque development, concentrated only on epidermal cells (keratinocytes) [10]. Previously published articles about the pathogenesis of psoriasis estimated the activity of fibroblasts, neutrophils and mast cells, neurons, endothelial cells, T lymphocytes and dendritic cells, as well as T cells clones [11-19]. In skin eruptions characteristic for psoriasis, the presence of excessive expression of proinflammatory cytokines such as: tumour necrosis factor $\alpha$ (TNF- $\alpha$ ), interferon $\gamma(\mathrm{IFN}-\gamma)$, interleukin 6 (IL-6), IL-8, IL-12, IL-17, $\mathrm{IL}-18$, transforming growth factor $\alpha$ (TGF- $\alpha$ ) and reduced concentration of anti-inflammatory cytokines (IL-10 and IL-4) has been found. In the pathogenesis of psoriasis, probably the most important role is played by some of the proinflammatory cytokines (TNF- $\alpha$, IL-12, IL-23, IL-17 and IFN- $\gamma$ ). T helper 17 (Th17) cells producing IL-22 and IL-17 have a potential function in the pathogenesis of psoriasis. IL-22 is an effector cytokine produced by T cells and is functionally connecting the immune system with epithelial cells. Moreover, IL-22 is stimulating cells to proliferation. Th17 cells are stimulated by IL-23 produced by dendritic cells $[5,20]$. Initially, mainly IFN- $\gamma$ seems to be responsible for the development of psoriatic skin changes [21]. On the basis of the current data it can be stated that the mechanism of the psoriatic plaque development is very complex. In this process a crucial role is played by the cells of the immune system and by cytokines produced by those cells. Both, immunocompetent cells and cytokines create a specific network of complicated bindings that lead to hyperproliferation of keratinocytes.

Heat shock proteins (HSPs) represent a high percentage (5-10\%) of intracellular proteins. Their concentration might increase several times as a result of activity of stress factors resulting in production of incorrectly folded or aggregated proteins. Stress factors such as heat shock, oxidative stress, infections, nitrogen oxide (NO), ultraviolet (UV), ethanol, heavy metal ions, proinflammatory factors (TNF- $\alpha$, IFN- $\gamma$ ), non-steroidal anti-inflammatory drugs (for example ibuprofen) cause stimulation of biosynthesis of different types of HSPs. Factors, which secondarily, through induction of oxidative stress, stimulate expression of HSPs, include: smoking cigarettes, diabetes mellitus, hyperlipidaemia, hypertension, coronary heart disease [22]. Heat shock proteins, especially HSP90, take part in processes associated with cardiac hypertrophy and myocardial fibrosis. Complex HSP90/CDC37 (Cell division cycle 37) is an integral component of TGF- $\beta$ in cardiac hypertrophy. Use of the HSP9O inhibitor in both in vivo and in vitro models caused reduction in collagen synthesis [23]. In the process of carcinogenesis, HSP90 stabilizes active forms of oncoproteins [24] as well as affects cell-cycle progression, apoptosis, angiogenesis and cancer cells ability to metastasis [25]. The HSP90 fam- ily also includes among others: proteins HSP90 $\alpha$, HSP90 $\beta$, glucose regulated protein 94 (GRP94). HSP90 proteins are necessary for maintaining the activity and stability of different proteins including among others: kinases, some of transcription factors or for steroid hormone receptors [26]. Heat shock protein HSP9O is composed of two subunits $\alpha$ and $\beta$, and is one of the adenosine triphosphate (ATP)-dependent proteins. HSP9O is composed of three structural domains: $\mathrm{N}$-terminal domain that has a polypeptides-binding pocket, middle domain and C-terminal domain [27]. Truncation of C-terminal domain from HSP9O results in a 5 -fold reduction in activity of ATPase [28]. While binding with proteins like p23, HSP70, CDC37, HSP90 forms protein complexes responsible for signal transduction and regulation of the transcription [29]. HSP90 controls activity of many factors regulating inflammation and immune response, for example proteins Janus kinase/signal transducers and activators of transcription (JAK/STAT), Toll-like receptor 4 (TLR-4) and

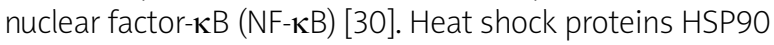
and HSP60, HSP70 induce maturation of blood-derived dendritic cells, and by increasing synthesis of IL-12 those HSPS enhance efficiency of antigen-presenting functions [31].

\section{Material and methods}

Material for the study included skin biopsies collected from patients with confirmed diagnosis of psoriasis. The control material included skin biopsies collected from healthy volunteers. Collected skin biopsies were stored in liquid nitrogen until the time of the molecular analysis.

\section{Characteristics of the study group}

For research we used 40 skin biopsies collected from 40 people, 20 women and 20 men, at the age from 18 to 84 years (mean age: 48.85 years). All patients had diagnosis of psoriasis confirmed by histopathological examination.

\section{Characteristics of the control group}

For research we used 20 skin biopsies collected from 20 people, 11 men and 9 women, at the age from 28 to 72 years (mean : 45.30 years). The control group consisted of healthy people in whom no acute infections, coexisting chronic diseases (diabetes mellitus, hyperlipidaemia, atherosclerosis, cardiovascular diseases such as coronary artery disease, hypertension), cancers, chronic inflammatory skin diseases or hormonal disorders were found.

\section{Molecular research}

Because of the complexity of the procedure and risk of degradation of genetic material during the research, expression of the gene encoding HSP9O protein on the mRNA synthesis level was divided into 3 stages: isolation of total RNA, reverse transcription polymerase chain reaction (RT-PCR), and quantitative analysis RT-PCR (qRT-PCR). 
Total RNA was isolated using A@A Biotechnology kit according to the manufacturer's recommendations. Each time after the isolation, qualitative and quantitative analysis of obtained material was made using spectrophotometer Eppendorf BioSpectrometer comparing the ratio of absorbance at 260 and $280 \mathrm{~nm}$ (A260/A280). The degree of degradation was measured using agarose gel electrophoresis in 2\% agarose gel in a 1 X TBE buffer. Results were compared with the marker at a size of $K B L 1$ RTU (100-1000) from A\&A Biotechnology ${ }^{\circledR}$. As control material we used RNA isolated from freshly drawn peripheral blood. Electrophoretic conditions were as follows: 30 min and $100 \mathrm{~V}$. In samples containing high molecular weight, purified RNA, the concentration values were standardized to the level of 75-100 $\mathrm{ng} / \mu \mathrm{l}$.

To perform reverse transcription polymerase chain reaction we used OneStep RT-PCR kit from EURx, which enables obtaining CDNA during one reaction in one tube. RT-PCR reaction was performed in thermocycler Mastercycler Personal Eppendorf.

Quantitative Analysis qRT-PCR was performed using intercalating dyes EvaGreen and Relative Quantification. As a reference gene we used G6PD (Glucose-6-phosphate dehydrogenase). The reaction was performed in thermocycler LightCycler 2.0.

\section{Ethics}

This study was approved by the Research Ethics Committee of the Collegium Medicum in Bydgoszcz.

\section{Results}

The mean level of expression of the HSP9O gene at the mRNA level in the study group amounted to 380.0 \pm 279 .0 whereas in the control group $81.8 \pm 29$.8. Statistical analysis showed a significantly higher concentration of analysed genetic material in psoriatic patients than in healthy volunteers $(p<0.001)$ (Table 1$)$.

Analysis of correlation between mRNA expression of the HSP9O gene and parameters describing the clinical course of psoriasis (duration of disease, duration of exacerbation, frequency of exacerbations within 1 year) showed a positive correlation between intensification of mRNA expression of the HSP9O gene and frequency of exacerbations of the disease throughout the year (Table 2).

\section{Evaluation of relation of mRNA expression of the HSP90 gene and chosen parameters in the study group}

The mRNA expression of the HSP90 gene was evaluated in relation to the type of psoriasis, clinical manifestation, coexistence of cardiovascular diseases and lipid disorders. Also the relationship between mRNA expression of the HSP9O gene and factors exacerbating psoriasis such as smoking cigarettes, drinking alcohol, stress and infections was analysed.

\section{Type of psoriasis}

Statistical analysis of the level of mRNA expression of the HSP90 gene between patients with type I and II psoriasis showed 1.5-fold higher mean expression of the analysed gene in patients with type I psoriasis (Table 3). However it was not a statistically significant difference ( $p=0.388)$.

Comparative analysis of clinical parameters of patients with type I and II psoriasis indicates differentiation of patients' age, which in patients with type I psoriasis was statistically significantly higher than in patients with type II (44.8 and 54.9 years, respectively; $p=0.029$ ) (Table 4).

Further analysis showed that parameters such as the number of previous hospitalizations and frequency of exacerbations of psoriasis within 1 year statistically significantly

Table 1. Comparison of mRNA expression of the HSP90 gene in psoriatic patients and healthy volunteers $(p<0.001)$

\begin{tabular}{|c|c|c|c|c|c|c|c|c|c|}
\hline \multirow[t]{2}{*}{ Group } & \multicolumn{8}{|c|}{ Descriptive statistics } & \multirow[t]{2}{*}{$P$-value } \\
\hline & $N$ & $\bar{x}$ & SD & Min. & $\mathrm{Q}_{1}$ & Me & $Q_{3}$ & Max. & \\
\hline Studied & 40 & 380.8 & 279.0 & 38.4 & 198.8 & 275.2 & 502.6 & 1190.0 & $<0.001$ \\
\hline Control & 20 & 81.8 & 29.8 & 45.5 & 61.2 & 77.2 & 94.3 & 180.2 & \\
\hline
\end{tabular}

Table 2. Correlations of analysed variables in patients with psoriasis

\begin{tabular}{|c|c|c|c|c|}
\hline \multirow[t]{2}{*}{ Variable } & \multicolumn{4}{|c|}{$\begin{array}{l}\text { Study group } \\
\text { Correlations of variables using Spearman's rank correlation test }\end{array}$} \\
\hline & Age & HSP90 & Duration of disease & Duration of exacerbation \\
\hline HSP90 & -0.10 & & & \\
\hline Duration of disease & 0.37 & 0.06 & & \\
\hline Duration of exacerbation & 0.17 & 0.09 & 0.06 & \\
\hline Frequency of exacerbations throughout the year & -0.26 & 0.71 & -0.02 & 0.00 \\
\hline
\end{tabular}


Rafał Czajkowski, Sebastian Kaszewski, Tadeusz Tadrowski, Dariusz Grzanka, Justyna Ziandarska, Gerard Drewa, Luiza Marek-Józefowicz

Table 3. Results of descriptive statistics of mRNA expression of the HSP90 gene in patients with the first or second type of psoriasis

\begin{tabular}{|c|c|c|c|c|c|c|c|c|c|}
\hline \multirow[t]{2}{*}{ Type of psoriasis } & \multicolumn{8}{|c|}{ Descriptive statistics } & \multirow[t]{2}{*}{$P$-value } \\
\hline & $N$ & $\bar{x}$ & SD & Min. & $Q_{1}$ & $\mathrm{Me}$ & $Q_{3}$ & Max. & \\
\hline First & 24 & 435.2 & 326.9 & 38.4 & 198.8 & 309.7 & 606.3 & 1190.0 & 0.388 \\
\hline Second & 16 & 299.3 & 163.3 & 93.8 & 187.6 & 257.8 & 371.9 & 626.0 & \\
\hline
\end{tabular}

Table 4. Results of descriptive statistics of the age between groups with the first and second type of psoriasis

\begin{tabular}{|c|c|c|c|c|c|c|c|c|c|}
\hline \multirow[t]{2}{*}{ Type of psoriasis } & \multicolumn{8}{|c|}{ Descriptive statistics } & \multirow[t]{2}{*}{$P$-value } \\
\hline & $N$ & $\bar{x}$ & SD & Min. & $\mathrm{Q}_{1}$ & $\mathrm{Me}$ & $Q_{3}$ & Max. & \\
\hline First & 24 & 44.8 & 19.1 & 18.0 & 29.0 & 38.5 & 57.0 & 84.0 & 0.029 \\
\hline Second & 16 & 54.9 & 10.5 & 40.0 & 47.5 & 55.0 & 64.5 & 72.0 & \\
\hline
\end{tabular}

Table 5. Relationship between the type of psoriasis and the number of previous hospitalizations

\begin{tabular}{cccccccc}
\hline \multirow{2}{*}{ Type of psoriasis } & \multicolumn{5}{c}{ Number of hospitalizations } & P-value \\
\cline { 2 - 7 } & & Zero & One & Two & Three & Several/many & \\
\hline I & $N$ & 0 & 4 & 1 & 1 & 9 & 0.047 \\
& $\%$ & 0.00 & 26.67 & 6.67 & 6.67 & 60.0 \\
\hline$\|$ & $N$ & 1 & 5 & 3 & 0 & 2 & \\
\cline { 2 - 7 } & $\%$ & 9.09 & 45.45 & 27.27 & 0.00 & 9.09 \\
\hline
\end{tabular}

Table 6. Relationship between the type of psoriasis and frequency of exacerbations throughout the year

\begin{tabular}{|c|c|c|c|c|c|c|c|}
\hline \multirow{2}{*}{\multicolumn{2}{|c|}{ Type of psoriasis }} & \multicolumn{5}{|c|}{ Frequency of exacerbations } & \multirow[t]{2}{*}{$P$-value } \\
\hline & & $1 \times /$ year & $2 \times /$ year & $3 \times /$ year & $3-4 \times /$ year & $4 \times /$ year & \\
\hline \multirow[t]{2}{*}{ I } & $N$ & 8 & 8 & 4 & 3 & 1 & 0.008 \\
\hline & $\%$ & 33.33 & 33.33 & 16.67 & 12.50 & 4.17 & \\
\hline \multirow[t]{2}{*}{$\|$} & $N$ & 8 & 6 & 2 & 0 & 0 & \\
\hline & $\%$ & 50.00 & 37.50 & 12.50 & 0.00 & 0.00 & \\
\hline
\end{tabular}

Table 7. Results of descriptive statistics for mRNA expression of the HSP9O gene in patients with different clinical presentation of psoriasis

\begin{tabular}{|c|c|c|c|c|c|c|c|c|c|}
\hline \multirow{2}{*}{$\begin{array}{l}\text { Clinical presentation } \\
\text { of psoriasis }\end{array}$} & \multicolumn{8}{|c|}{ Descriptive statistics } & \multirow[t]{2}{*}{$P$-value } \\
\hline & $N$ & $\bar{x}$ & SD & Min. & $\mathrm{Q}_{1}$ & $\mathrm{Me}$ & $\mathrm{Q}_{3}$ & Max. & \\
\hline Plaque & 21 & 386.1 & 307.5 & 38.4 & 204.5 & 275.2 & 495.9 & 1190.0 & 0.84 \\
\hline Pustular & 4 & 382.5 & 365.7 & 139.5 & 148.1 & 236.2 & 616.9 & 918.0 & \\
\hline Erythrodermic & 5 & 290.8 & 142.4 & 193.0 & 204.3 & 234.5 & 377.3 & 501.0 & \\
\hline Psoriatic arthritis & 10 & 404.7 & 246.9 & 75.0 & 229.5 & 322.8 & 598.3 & 852.5 & \\
\hline
\end{tabular}

differed between analysed groups of patients with type I and II psoriasis. Patients with type I psoriasis were hospitalized substantially more frequently (Table 5) and they also had more frequent exacerbations of the disease (Table 6).

\section{Clinical presentation of psoriasis}

Analysis of levels of mRNA expression of the HSP9O gene in groups of patients with various types of psoriasis showed a not significantly lower mean level of ex- pression in erythrodermic psoriasis (290.8) in relation to pustular psoriasis (382.5) and plaque psoriasis (386.1), whereas the highest concentration of the analysed factor was found in psoriatic arthritis (404.7). Comparison that was made between four analysed groups using KruskalWallis ANOVA test did not find statistically significant differences confirming the fact that the type of psoriasis has an influence on expression of the gene of the analysed protein (Table 7). 


\section{Coexisting diseases}

The relationship between mRNA expression of the HSP90 gene and coexistence of cardiovascular diseases and lipid disorders was also analysed. mRNA expression of the HSP9O gene was analysed in patients with negative and positive medical history for cardiovascular diseases (hypertension, coronary artery disease), lipid disorders and diabetes mellitus.

\section{Cardiovascular disorders}

Comparative analysis of the differences in mRNA expression of the HSP90 gene between patients from the study group with negative and positive medical history for cardiovascular diseases showed that there were no statistically significant differences (400.8 vs. 353.9 , respectively; $p=0.892$ ) (Table 8 ). It indicates that there was no relationship between coexistence of cardiovascular diseases in patients with psoriasis and the level of mRNA expression of the HSP9O gene.

\section{Lipid metabolism disorders}

Comparison made to define differences in mRNA expression of the HSP9O gene between patients with negative and positive medical history for lipid disorders showed that there were no statistically significant differences between the two groups (365.7 vs. 416.3, respectively; $p=0.651$ ) (Table 9). It indicates that there was no relationship between analysed variables.

Psoriatic patients with a positive medical history for hyperlipidaemia in a statistically significant way showed a negative correlation between age and mRNA expression of the HSP90 gene, because with age, the expression of the analysed gene decreases.

\section{Diabetes mellitus}

Comparison made to define differences in $\mathrm{mRNA}$ expression of the HSP90 gene between patients with negative and positive medical history for diabetes mellitus showed that there were no statistically significant differences between the two groups (384.2 vs. 361.8, respectively; $p=0.839$ ) (Table 10).

It indicates that there was no relationship between the level of mRNA expression of the HSP9O gene and coexistence of diabetes mellitus in patients with psoriasis.

\section{Factors exacerbating psoriasis}

The relationship between the level of mRNA expression of the HSP9O gene and factors that might exacerbate the course of psoriasis was also estimated. Factors such as smoking cigarettes, drinking alcohol, stress and infections were analysed.

\section{Smoking cigarettes}

Comparison made to define differences in mRNA expression of the HSP9O gene between non-smoking patients (negative history) and smoking patients (positive history) showed that there was no statistically significant correlation between them, below the level of assumed coefficient $\alpha$. However, a higher mean level of mRNA expression of the HPS90 gene in patients smoking

Table 8. Results of descriptive statistics for mRNA expression of the HSP90 gene between patients with negative and positive medical history for cardiovascular diseases

\begin{tabular}{|c|c|c|c|c|c|c|c|c|c|}
\hline \multirow{2}{*}{$\begin{array}{l}\text { Medical history for } \\
\text { cardiovascular diseases }\end{array}$} & \multicolumn{8}{|c|}{ Descriptive statistics } & \multirow[t]{2}{*}{$P$-value } \\
\hline & $N$ & $\bar{x}$ & SD & Min. & $\mathbf{Q}_{1}$ & Me & $\mathrm{Q}_{3}$ & Max. & \\
\hline Negative & 23 & 400.8 & 318.6 & 38.4 & 193.0 & 315.5 & 501.0 & 1190.0 & 0.892 \\
\hline Positive & 17 & 353.9 & 220.9 & 114.9 & 215.5 & 258.5 & 504.1 & 852.5 & \\
\hline
\end{tabular}

Table 9. Results of descriptive statistics for mRNA expression of the HSP9O gene between patients with negative and positive medical history for hyperlipidaemia

\begin{tabular}{|c|c|c|c|c|c|c|c|c|c|}
\hline \multirow{2}{*}{$\begin{array}{l}\text { Medical history for } \\
\text { hyperlipidaemia }\end{array}$} & \multicolumn{8}{|c|}{ Descriptive statistics } & \multirow[t]{2}{*}{$P$-value } \\
\hline & $N$ & $\bar{x}$ & SD & Min. & $\mathrm{Q}_{1}$ & $\mathrm{Me}$ & $\mathrm{Q}_{3}$ & Max. & \\
\hline Negative & 28 & 365.7 & 282.2 & 38.4 & 204.3 & 259.7 & 464.5 & 1190.0 & 0.651 \\
\hline Positive & 12 & 416.3 & 280.2 & 123.7 & 180.6 & 322.8 & 620.2 & 918.0 & \\
\hline
\end{tabular}

Table 10. Results of descriptive statistics for mRNA expression of the HSP90 gene between patients with negative and positive medical history for diabetes mellitus

\begin{tabular}{|c|c|c|c|c|c|c|c|c|c|}
\hline \multirow{2}{*}{$\begin{array}{l}\text { Medical history for } \\
\text { diabetes mellitus }\end{array}$} & \multicolumn{8}{|c|}{ Descriptive statistics } & \multirow[t]{2}{*}{$P$-value } \\
\hline & $N$ & $\bar{x}$ & SD & Min. & $\mathrm{Q}_{1}$ & Me & $\mathrm{Q}_{3}$ & Max. & \\
\hline Negative & 34 & 384.2 & 292.4 & 38.4 & 193.0 & 275.2 & 501.0 & 1190.0 & 0.839 \\
\hline Positive & 6 & 361.8 & 205.9 & 156.7 & 218.5 & 277.7 & 598.3 & 642.0 & \\
\hline
\end{tabular}


Rafał Czajkowski, Sebastian Kaszewski, Tadeusz Tadrowski, Dariusz Grzanka, Justyna Ziandarska, Gerard Drewa, Luiza Marek-Józefowicz

Table 11. Results of descriptive statistics of mRNA expression of the HSP90 gene between patients with factors exacerbating psoriasis such as stress and acute infections

\begin{tabular}{|c|c|c|c|c|c|c|c|c|c|}
\hline \multirow[t]{2}{*}{ Medical history } & \multicolumn{8}{|c|}{ Descriptive statistics } & \multirow[t]{2}{*}{$P$-value } \\
\hline & $N$ & $\bar{x}$ & SD & Min. & $Q_{1}$ & Me & $Q_{3}$ & Max. & \\
\hline Stress & 11 & 327.5 & 373.8 & 38.4 & 114.9 & 229.5 & 918.0 & 993.0 & 0.008 \\
\hline Infection & 6 & 542.0 & 334.1 & 243.5 & 395.1 & 426.6 & 570.5 & 1190.0 & \\
\hline Stress/infection & 11 & 384.8 & 180.1 & 93.8 & 218.5 & 298.5 & 495.9 & 642.0 & \\
\hline
\end{tabular}

cigarettes (437.3 vs. 343.2) with p-value of 0.052 occurred on the level of statistical tendency (from 0.05 to 0.10 ), what might indicate the presence of differences between groups. For confirmation of those results the analysis on the larger group of psoriatic patients should be done.

\section{Drinking alcohol}

Comparison that was made refers to differences in levels of mRNA expression of the HSP90 gene between patients not consuming (negative history) and consuming alcohol (positive history) and showed a correlation between them that was not statistically significant, below the level of assumed coefficient a (366.3 vs. 419.0, respectively; $p=0.283$ ).

\section{$\underline{\text { Stress and acute infections }}$}

Comparison that was made refers to the relationship between factors exacerbating psoriasis and occurrence of differences in mRNA expression of the HSP 90 gene.

The comparison between analysed exacerbating factors (stress, acute infections and together stress/acute infections) was made using the Kruskal-Wallis ANOVA test and it showed that the differences were statistically significant, what confirmed the influence of the abovementioned factors on the level of mRNA expression of the HSP90 gene, $p$-value was 0.008 (Table 11).

Conducted research showed that the strongest factor inducing the increase of mRNA expression of the HSP9O gene for the analysed group of patients was infections. Stress induced production of the analysed protein the least significantly.

\section{Discussion}

Studies have shown that heat shock proteins play an important role in the pathogenesis of many inflammatory diseases and in the shaping of immune responses. Expression of the HSP90 protein is observed in the whole normal epidermis [32], whereas overexpression was demonstrated among others in diseases like breast cancer, lung cancer, leukaemia, Hodgkin's lymphoma, systemic lupus erythematosus, rheumatoid arthritis, cardiovascular disorders, sleep apnoea, psoriasis [33, 34]. Moreover HSP90 protein plays an important role in neurodegen- erative diseases such as Alzheimer's disease, Parkinson's disease and Huntington's disease [35, 36].

Kakeda et al. in their study found a significantly increased expression of HSP9O protein in epidermal keratinocytes and mast cells in the tissue samples obtained from lesional psoriatic skin [34]. Whereas DamasiewiczBodzek et al. found that the sera of the psoriatic patients contain higher concentrations of anti-HSP9O antibodies than in the control group [37].

In this study, a relationship between mRNA expression of the gene encoding HSP90 protein and frequency of exacerbations of psoriasis within 1 year was noted. The level of mRNA expression of the HSP90 gene was higher in patients with three and four exacerbations of psoriasis within 1 year. There was no correlation between mRNA expression of the HSP9O gene and duration of psoriasis as well as duration of a specific exacerbation. Further analysis showed more frequent exacerbations of psoriasis within 1 year in patients with the first type of psoriasis. This group of patients was also more frequently hospitalized. These results coincide with available literature data and according to them, type I psoriasis is characterized by a more severe course and more frequent recurrences $[3,38]$.

On the basis of the above-mentioned facts it might be concluded that activity of an additional stress factor triggering exacerbations every time provokes release of additional "deposits" of HSP9O protein despite the previous presence of chronic inflammation. It seems that duration of the disease and time of activity of the stimulus that provoked exacerbation on the background of previously present inflammation are less important for the level of HSP9O expression. The study evaluated the influence of factors such as smoking, drinking alcohol, acute infections and stress on mRNA expression of the HSP90 gene.

One of processes taking place in cells of smoking people is production of reactive oxygen species. With age, production of free radicals increases, whereas defence mechanisms of the organism decrease [39]. This study proved that there was no correlation between mRNA expression of the HSP90 gene and smoking or drinking alcohol.

Infections and stress might lead to activation of heat shock proteins. Because of the fact that HSPs found in microorganisms have a high degree of sequence homol- 
ogy with human HSPs, they work as factors influencing immunogenicity. Exacerbation of psoriasis caused by streptococcal infection is associated with involvement of HSPs in immune response. Among factors exacerbating psoriasis which were included in the study, acute infections were elements that induced mRNA expression of the HSP90 gene in the strongest manner. In relation to data about a more severe course of erythrodermic and pustular psoriasis, the correlation between clinical presentation of the disease and the level of mRNA expression of the HSP90 gene was analysed. However in conducted research, no increased mRNA expression of the HSP90 gene was found in any type of psoriasis. There was also no correlation between arthralgia caused by psoriatic arthritis or osteoarthritis and expression of the evaluated gene. The available literature does not present data about expression of HSP proteins depending on the clinical presentation of psoriasis.

The study also analysed mRNA expression of the HSP90 gene in patients with psoriasis and a positive medical history of cardiovascular diseases such as hypertension and coronary heart disease. According to the literature, heat shock proteins are one of the basic components of cardiomyocytes. Their increased expression is caused by ischemia, overload of the heart and heart failure. Impairment of heat shock proteins' function results in loss of ability to deal with stress factors and in reduced cardioprotective potential [40].

In conducted studies there was no evidence of increased mRNA expression of the HSP9O gene in patients with psoriasis and coexisting cardiovascular diseases. The available literature also does not contain data about the activity of HSP9O protein in patients with psoriasis and coexisting positive medical history for hypertension or coronary heart disease.

Some of the researchers think that psoriasis should be treated as a prediabetes condition [41]. In the course of diabetes mellitus and other metabolic diseases there was found an impaired function of many HSP proteins including HSP70 and HSP9O that are key regulators of mechanisms associated with the development of complications in the course of diabetes mellitus. However results of this study have not shown any correlation between the level of mRNA expression of the HSP9O gene and presence of diabetes mellitus in the group of examined patients. In case of dyslipidaemia the first elements that are affected by an increased serum level of lipids are endothelial cells. As it is known, defects of cell structure and impaired functioning of those cells play an important role in the pathogenesis of many disorders. Foam cells, formed by accumulation of lipids in endothelial cells, are characterized, among others, by a high level of heat shock proteins such as HSP27, HSP70 and HSP9O [42].

Proved relationship between psoriasis and lipid disorders was the basis for searching for a correlation between mRNA expression of the HSP9O gene and co- existence of lipid disorders. Results of this study proved that there was no correlation between the level of mRNA expression of the HSP90 gene and coexistence of hyperlipidaemia in the group of examined patients. However, in this study it was remarked that there was a correlation between age and mRNA expression of the HSP9O gene in psoriatic patients with a positive medical history for hyperlipidaemia. The results demonstrated a negative correlation between those parameters: with the age a decreasing level of mRNA expression of the HSP9O gene was observed. A similar relationship was found in patients with a positive medical history for diabetes mellitus. The literature does not present unequivocal data concerning the correlation between activity of HSP9O protein and coexisting metabolic disorders such as diabetes mellitus or hyperlipidaemia in psoriatic patients.

Available publications and results of this study suggest that HSP9O from keratinocytes and mast cells is one of key regulators of the inflammation so inhibition of HSP90 protein's activity might be a new therapeutic option to treat psoriasis.

\section{Conclusions}

HSP90 protein plays an important role in the pathogenesis of psoriasis. Expression of the gene encoding HSP90 protein at the MRNA level correlates with the frequency of exacerbations of psoriasis within 1 year. Among factors exacerbating psoriasis, infection induces mRNA expression of the gene encoding HSP9O protein most significantly. Comorbidity of cardiovascular diseases, diabetes, smoking, drinking of alcohol does not influence significantly the mRNA expression of the gene encoding HSP9O protein in patients with psoriasis.

\section{Conflict of interest}

The authors declare no conflict of interest.

\section{References}

1. Nestle FO, Kaplan DH, Barker J. Psoriasis. N Engl J Med 2009; 361: 496-509.

2. Schafer T. Epidemiology of psoriasis. Review and the German perspective. Dermatology 2006; 212: 327-37.

3. Burgdorf WHC, Plewig G, Wolff HH, et al. Braun-Falco. Dermatologia. Gliński W, Czarnecka-Operacz M, Krasowska D, et al. Wydawnictwo Czelej, Lublin 2010.

4. Bolognia JL, Jorizzo JL, Rapini RP. Dermatology. $2^{\text {nd }}$ ed. Mosby Elsevier 2008.

5. Adamski Z, Linke K, Szmborski W. Leczenie biologiczne w dermatologii, gastroenterologii i reumatologii u dorosłych i dzieci. Termedia, Poznań 2015.

6. Junko T, Sungat G, Sinéad M. Psoriasis and comorbid diseases. Part I. Epidemiology J Am Acad Dermatol 2017; 76: 377-90.

7. Gelfand JM, Neimann AL, Shin DB, et al. Risk of myocardial infarction in patients with psoriasis. JAMA 2006; 296: 1735-41. 
8. Ahlehoff O, Gislason GH, Charlot M, et al. Psoriasis is associated with clinically significant cardiovascular risk: a Danish nationwide cohort study. J Intern Med 2011; 270: 147-57.

9. Gelfand JM, Troxel AB, Lewis JD, et al. The risk of mortality in patients with psoriasis: results from a population-based study. Arch Dermatol 2007; 143: 1493-9.

10. Barker JN. The pathophysiology of psoriasis. Lancet 1991; 338: 227-30.

11. Saiag P, Coulomb B, Lebreton C, et al. Psoriatic fibroblasts induce hyperproliferation of normal keratinocytes in a skin equivalent model in vitro. Science 1985; 230: 669-72.

12. Ackermann L, Harvima IT, Pelkonen J, et al. Mast cells in psoriatic skin are strongly positive for interferon-gamma. Br J Dermatol 1999; 140: 624-33.

13. Raychaudhuri SP, Rein G, Farber EM. Neuropathogenesis and neuropharmacology of psoriasis. Int J Dermatol 1995; 34: 685-93.

14. Lowe PM, Lee ML, Jackson CJ, et al. The endothelium in psoriasis. Br J Dermatol 1995; 132: 497-505.

15. Gottlieb AB. Immunologic mechanisms in psoriasis. J Am Acad Dermatol 1988; 18: 1376-80.

16. Valdimarsson H, Baker BS, Jónsdóttir I, et al. Psoriasis: a Tcell-mediated autoimmune disease induced by streptococcal superantigens? Immunol Today 1995; 16: 145-9.

17. Nickoloff BJ. The immunologic and genetic basis of psoriasis. Arch Dermatol 1999; 135: 1104-10.

18. Chang JC, Smith LR, Froning KJ, et al. Persistence of T-cell clones in psoriatic lesions. Arch Dermatol 1997; 133: 703-8.

19. Vollmer S, Menssen A, Prinz JC. Dominant lesional T cell receptor rearrangements persist in relapsing psoriasis but are absent from nonlesional skin: evidence for a stable antigen-specific pathogenic T cell response in psoriasis vulgaris. J Invest Dermatol 2001; 117: 1296-301.

20. Zheng Y, Danilenko DM, Valdez P, et al. Interleukin-22, a T(H)17 cytokine, mediates IL-23-induced dermal inflammation and acanthosis. Nature 2007; 445: 648-51.

21. Nickoloff BJ, Nestle FO. Recent insights into the immunopathogenesis of psoriasis provide new therapeutic opportunities. J Clin Invest 2004; 113: 1664-75.

22. Van Eden W, Van der Zee R, Prakken B. Heat-shock proteins induce T-cell regulation of chronic inflammation. Nat Rev Immunol 2005; 5: 318-30.

23. Datta R, Bansal T, Rana S, et al. HSP90/Cdc37 assembly modulates TGF- $\beta$ receptor-II to act as a profibrotic regulator of TGF- $\beta$ signaling during cardiac hypertrophy. Cell Signal 2015; 27: 2410-24.

24. Workman P, Burrows F, Neckers L, et al. Drugging the cancer chaperone HSP90: combinatorial therapeutic exploitation of oncogene addiction and tumor stress. Ann N Y Acad Sci 2007; 1113: 202-16.

25. Messaoudi S, Peyrat Jf, Brion JD, et al. Heat-shock protein 90 inhibitors as antitumor agents: a survey of the literature from 2005 to 2010. Expert Opin Ther Pat 2011; 21: 1501-42.

26. Butler M, Ferraldeschi R, Armstrong H. Maximizing the therapeutic potential of HSP9O inhibitors. Mol Cancer Res 2015; 13: 1445-51.

27. Garnier C, Lafitte D, Tsvetkov P. Binding of ATP to heat shock protein 90: evidence for an ATP-binding site in the C-terminal domain. J Biol Chem 2002; 277: 12208-14.

28. Prodromou C, Panaretou B, Chohan S, et al. The ATPase cycle of Hsp90 drives a molecular 'clamp' via transient dimerization of the N-terminal domains. EMBO J 2000; 19: 4383-92.
29. Pratt WB, Toft DO. Regulation of signaling protein function and trafficking by the hsp90/hsp70-based chaperone machinery. Exp Biol Med 2003; 228: 111-33.

30. Adhikari N, Charles N, Lehmann U, et al. Transcription factor and kinase-mediated signaling in atherosclerosis and vascular injury. Curr Atheroscler Rep 2006; 8: 252-60.

31. Curry J, Gin J, Bonish B, et al. Innate immune-related receptors in normal and psoriatic skin. Arch Pathol Lab Med 2003; 127: 178-86

32. Boehncke W, Dahlke A, Zollner T, et al. Differential expression of heat shock protein 70 (hsp70) and heat shock cognate protein 70 ( $\mathrm{Hsc70}$ ) in human epidermis. Arch Dermatol Res 1994; 287: 68-71.

33. Hsu P, Hsu S. Abundance of heat shock proteins (hsp89, hsp60, and hsp27) in malignant cells of Hodgkin's disease. Cancer Research 1998; 58: 5507-13.

34. Kakeda M, Arock M, Schlapbach C, et al. Increased expression of heat shock protein 90 in keratinocytes and mast cells in patients with psoriasis. J Am Acad Dermatol 2014; 70: 683-90.

35. Bohush A, Bieganowski P, Filipek A. Hsp90 and its co-chaperones in neurodegenerative diseases. Int J Mol Sci 2019; 20: 4976.

36. Hoter A, El-Sabban M, Naim H. The HSP90 family: structure, regulation, function, and implications in health and disease. Int J Mol Sci 2018; 19: 2560.

37. Damasiewicz-Bodzek A, Szumska M, Tyrpień-Golder K. Antibodies to heat shock proteins $90 \alpha$ and $90 \beta$ in psoriasis. Arch Immunol Ther Exp (Warsz) 2020; 68: 9.

38. Wolska H, Langner A. Łuszczyca. Czelej, Lublin 2006.

39. Trüeb R. The impact of oxidative stress on hair. Int I Cosmet Sci 2015; 37 Suppl 2: 25-30.

40. Kumarapeli AR, Wang X. Genetic modification of the heart: chaperones and the cytoskeleton. J Mol Cell Cardiol 2004; 37: 1097-109

41. Gyldenløve M, Vilsbøll T, Zachariae C, et al. Impaired incretin effect is an early sign of glucose dysmetabolism in nondiabetic patients with psoriasis. J Intern Med 2015; 278: 660-70.

42. Ivan L, Antohe F. Hyperlipidemia induces endothelial-derived foam cells in culture. J Recept Signal Transduct Res 2010; 30: 106-14. 